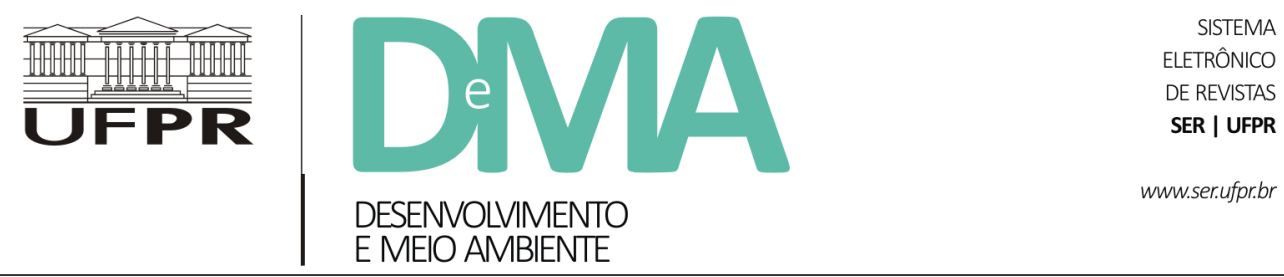

\title{
Biopoder, psicopoder y ecopoder
}

\section{Biopoder, psicopoder e ecopoder}

\section{Biopower, psychopower and ecopower}

\author{
Rafael GÜITRÓN TORRES ${ }^{1 *}$ \\ ${ }^{1}$ Universidad Pontificia Comillas, Madrid, Espanha. \\ *E-mail de contato: rguitron@comillas.edu
}

Artículo recibido el 19 de septiembre, 2018, versión final aceptada el 24 de marzo, 2019, publicado el 5 de agosto.

RESUMEN: La crisis termoambiental hodierna es el fenómeno que evidencia la crisis de la racionalidad económica instrumental imperante en nuestra civilización. Este hecho es responsabilidad del ser/hacer humano, por tanto, somos nosotros los que frente al ecocidio y la exclusión debemos tomar una elección sustentable que preserve la biodiversidad. A este propósito se analizan tres estrategias de poder: el biopoder (Foucault), el psicopoder (Byung-Chul Han) y el ecopoder (Leff y Naredo). La filosofía por amor a la verdad y al bien debe desenmascarar al biopoder, al psicopoder y al ecopoder; es un deber ético-político que no se puede eludir en este crepúsculo de la historia, ya que todos somos víctimas y cómplices. Al fin de cuentas, salvar la biosfera es salvar al hombre y viceversa.

Palabras-clave: víctima; biopoder; psicopoder; ecopoder; estrategias.

RESUMO: A crise termoambiental da contemporaneidade, é o fenômeno que evidencia a crise da racionalidade econômica instrumental que prevalece em nossa civilização. Esse fato é de responsabilidade do ser/fazer humano, portanto, somos nós que, diante do ecocidio e da exclusão, devemos fazer uma escolha sustentável que preserve a biodiversidade. Três estratégias de poder são analisadas para esse fim: biopoder (Foucault), psicopoder (ByungChul Han) e ecopoder (Leff e Naredo). A filosofia em prol da verdade e da bondade deve desmascarar o biopoder, psicopoder e ecopoder; é um dever ético-político que não pode ser evitado neste crepúsculo da história, pois somos todos vítimas e cúmplices. Afinal, salvar a biosfera é salvar o homem e vice-versa.

Palavras-chave: vítima; biopoder; psicopoder; ecopoder; estratégias.

Desenvolv. e Meio Ambiente usa uma Licença Creative Commons - Atribuição-NãoComercial-SemDerivações 4.0 Internacional 
ABSTRACT: The thermoenvironmental crisis is the phenomenon that evidences the crisis of instrumental economic rationality that prevails in our civilization. This fact is the responsibility of the human being (to do/make and to be), therefore, it is us who, in the face of ecocide and exclusion, must make a sustainable choice that preserves biodiversity. Three power strategies are analyzed: biopower (Foucault), psychopower (Byung-Chul Han) and ecopower (Leff and Naredo). The philosophy of truth and goodness must unmask biopower, psychopower and ecopower; it is an ethical-political duty that cannot be avoided in this twilight of history, since we are all victims and accomplices. After all, saving the biosphere is saving man and vice versa.

Keywords: victim; biopower; psicopower; ecopower; strategies.

\section{Introduction}

El literato nigeriano Tanure Ojaide ${ }^{1}$ escribió el poema titulado No tienes que ser, donde podemos encontrar estas fuertes llamadas a la conciencia moral:

No tienes que ser judío para temblar en la pesadilla de Auschwitz, no tienes que ser negro para sentir la agonía y la vergüenza de la esclavitud, no tienes que ser aborigen para ser herido por la arrogancia del descubrimiento, no tienes que ser extranjero para saber qué significa la discriminación, no tienes que ser minoría para comprender el dominio de los grandes números, no tienes que estar sin techo para atravesar los caprichos de la vida, no tienes que ser rico para temer la incertidumbre del mañana, no tienes que estar lisiado para sufrir el dolor de los discapacitados, no tienes que ser una estrella para contemplar fijamente la volatilidad del clima, sólo tienes que ser un ser humano para conocer los aprietos de los demás (Ojaide, 2013).

La letra del poeta disecciona anatómicamente la existencia biográfica, y ante esta panóptica emerge la tragedia y profecía de Walter Benjamin
(Benjamin, 2005) con el ángel de la historia (angelus novus). El poeta y el filósofo plasman la temática, uno en tinta escarlata y, el otro, tatúa el logos desencarnado de la historia.

La víctima es persona con dignidad, le es constitutivo un rostro, un nombre, una historia y un horizonte. El proceso histórico latinoamericano ha invitado a mirar atentamente al pobre, ya que su rostro se convierte en carne, presencia real de la deshumanidad que exige una respuesta. Por ello se comprende que el teólogo Jon Sobrino afirme "extra pauperes nulla salus" (Sobrino, 2007). Sin embargo, el concepto pobre transmutó por el de víctima, y, así se extiende el horizonte antropoético posibilitando, también, la lucha contra la jaula de hierro económica de M. Weber (Mitzman, 1976). Debemos afirmar, junto con la legión de pensadores, parafraseando a Sobrino, fuera de las víctimas no hay salvación. $\mathrm{La}$ tradición latinoamericana, partiendo de su herencia judeo-cristiana y ético-humanista, identifica a cada ser humano como persona digna de rescate y redención. La salvación levinasiana significa responsabilidad para con el otro y en favor del nosotros, su propósito es contrarrestar la negación de la dignidad

${ }^{1}$ Tanure Ojaide es un poeta nigeriano quien se caracteriza por un estilo de poesía sociopolítica. 
que se materializa en exclusión y cosificación. La responsabilidad sigue siendo un camino ascendente que debe ser constantemente reapropiado por lo auténticamente humano.

La palabra paz es la síntesis del bien, la verdad y la belleza, y demanda justicia social frente a un sistema de apariencias e intereses. Las cadenas de los poderes invisibles esclavizan, enajenan y alienan las conciencias y producen exclusión social, por lo que cabalgan libremente, galopando en las praderas de la descarnada estrategia de borrar el nombre, enmudecer la historia, esconder el rostro, vaciar el sentido y negar la dignidad de persona. La paz la construyen las personas libres y responsables con nombre y rostro: los que se atreven a narrar la historia con sentido ético-político, enfrentando y trascendiendo el lenguaje políticamente correcto; ellos declaran a los cuatro vientos que todo ser humano es persona, independientemente de las circunstancia en que se encuentren y en las encrucijadas existenciales de la andanza humana en que estarán.

Los siguientes párrafos analizan las estrategias de poder que afectan al hombre-víctima y al oikos "casa común", desde las dimensiones del bio, psico y eco poder. El trinomio bio-psico-eco comparte el denominador común del análisis epistemológico sobre el poder y sus estrategias. La economía ambiental y la economía ecológica están contribuyendo positivamente con sus análisis sobre la economía y la ecología para el bien de la biosfera en su conjunto. Existen numerosos artículos escritos sobre cambio climático, medio ambiente, la vida, la naturaleza, el antropoceno, limites, creatividad, etc. Y a través de todos ellos descubrimos un horizonte que exige ser tratado con mayor detenimiento: el poder. El filósofo colombiano Eduardo Mendieta ${ }^{2}$ acertadamente recuerda que "el poder es al sistema social lo que la informática al sistema informático. En ambos casos, ninguno existe fuera de lo que los realiza" (Mendieta, 2007). La aventura estriba en responder a la siguiente pregunta: ¿cómo intervienen las estrategias de poder en la relación sociedad y naturaleza?

Los objetivos de este articulo son: describir la idea de biopoder de Foucault y sus consecuencias en las estrategias de saber-poder; examinar el término de psicopoder de Byung-Chul Han, en cuanto, estrategia de control de la psique; reseñar la estrategia del ecopoder desde las aportaciones del filósofo de Enrique Leff y el economista Juan Manuel Naredo, quienes evidencian el daño ecológico y social de la biosfera; y, analizar en la conclusión la interrelación de los tres conceptos.

\section{El biopoder}

El concepto de biopoder fue utilizado por Michel Foucault en su libro Historia de la sexualidad I. La voluntad de saber, para poner de manifiesto el dominio del saber/poder humano sobre la biología, desarrollado sobre todo desde el siglo XIX posibilitado por el gran avance del conocimiento científico-técnico, y que se encarna en la vida política con la decidida pretensión de determinar "la vida misma... Ello implica que la vida es objeto de

\footnotetext{
${ }^{2}$ Eduardo Mendieta es profesor de filosofía en la Universidad estatal de Pennsylvania, EUA. Investiga las líneas de la Ética, Filosofía política, Filosofía Latinoamericana, Teoría critica, entre otras.
} 
un juicio político de valor tanto para seleccionarla como para mejorarla" (Bazzicalupo, 2016, p. 65). El poder sobre la vida adoptará, entre otras fórmulas, la forma de un saber en la cultura. El objetivo de estas nuevas tecnologías de gobierno es transformar el poder soberano de vida o muerte en "un poder que se ejerce positivamente sobre la vida, que procura administrarla, aumentarla, multiplicarla, ejercer sobre ella controles precisos y regulaciones generales" (Foucault, 2016, p. 145). Es un dominio que se ejerce sobre la vida por medio de estrategias de poder/saber en la cultura (Foucault, 1977, p. 168-169).

El objetivo de estas nuevas formas de ejercicio del poder/saber no es dar muerte, sino hacer vivir, transformando tanto el cuerpo-ser humano, asimilándolo a una máquina, como el cuerpo-especie humano, dando lugar a "una biopolítica de la población” (Foucault, 2016, p. 148). El binomio compuesto de cuerpo-producción y los procesos biológico-económicos están en la base del biopoder que "fue, a no dudarlo, un elemento indispensable en el desarrollo del capitalismo; este no pudo afirmarse sino al precio de la inserción controlada de los cuerpos en el aparato de producción y mediante un ajuste de los fenómenos de población a los procesos económicos" (Foucault, 2016, p. 149). Por ello, el capital/trabajo determina el sentido productivo de la sociedad. En este marco, el trabajo asumió una utilidad como valor de cambio, una especie de ADN productivo, pero puso en entredicho los aspectos humanos de autorrealización y socialización propios de la persona trabajadora.

La tarea de la filosofía ante la sociedad seducida, siguiendo la huella de Foucault, consiste en elaborar un pensamiento crítico para: clarificar la aparente neutralidad; desvelar el disfraz de la supuesta libertad; desenmascarar las estrategias de control; revertir el proceso anestesiante y paralizador; y evidenciar la violencia de ciertas racionalidades. La relación sujeto / verdad / poder implica que la "crítica se atribuye el derecho de interrogar a la verdad acerca de sus efectos de poder y al poder acerca de sus discursos de verdad" (Foucault, 2012, p. 21). Es evidente que la propuesta de Foucault no es solo una teoría sobre el poder, sino que "consiste en avanzar menos hacia una "teoría" que hacia una "analítica" del poder: quiero decir, hacia la definición del dominio específico que forman las relaciones de poder y la determinación de los instrumentos que permiten analizarlo" (Foucault, 2016, p. 86). Consiste en observar las prácticas verbales y no verbales, ambas expresión de la razón interna del saber/poder, es decir, investigar la racionalidad de las prácticas del poder ahogadas en el mar del silencio cómplice de los buenos. "El método adoptado es la genealogía: las verdades son indagadas en la persistencia y discontinuidad de las prácticas históricas y en sus efectos. Foucault identifica cada vez el eje histórico y contingente en cuyo ámbito un discurso evidencia saberes y prácticas que tiene pretensión de verdad y efectos de poder..." (Bazzicalupo, 2016, p. 66).

El individuo foucaultiano se confronta con los dispositivos de poder, ya que el cuerpo-ser humano se encuentra sometido y amalgamado a su propia identidad en prácticas y saberes. El individuo es a un tiempo objeto del poder y está sujeto al poder. La acción del sujeto crítico debe ser contra la dominación, la exclusión y la sumisión que asfixia. Este camino conduce a los análisis de la economía como poder de posesión, de la soberanía como poder jurídico, de la represión como poder de control, de los discursos como poderes de sujeción, de la neutralidad como 
poder de la indiferencia e inmovilidad, etc. La respuesta a la pregunta general conduce a argumentar sobre las estrategias, la historia, los objetivos, las instituciones, los sistemas y las racionalidades. El poder se refiere a los dispositivos que pretenden manipular conductivamente los comportamientos y disponer de sus posibilidades: por medio del estímulo que asume el biocapital como unidad de síntesis de la vida.

Foucault afirma que "toda relación de explotación es primariamente una relación política" (Foucault, 1976, p. 32-33), y sus efectos son evidentes: por un lado, la reproducción social encubre el fenómeno de la explotación constante; y, por el otro, instaura estrategias de dominio aparentemente libres, en cuanto que el contrato social es una cesión voluntaria del sujeto soberano, ya que por medio de una decisión individual se inserta en un engranaje social. Es, en resumidas cuentas, un vaciamiento histórico de las relaciones que se concretan en la microfisica del poder: atomizar y acumular (Osorio, 2006). El sistema de acumulación muestra algunos fenómenos alarmantes: la precariedad como precursor de la inestabilidad laboral; la libre circulación de las mercancías pero no de las personas; el desechar/descartarlas porque son jóvenes o porque superan los 40 años; el sedentarismo como fuente de enfermedades es una epidemia que desahucia en la inactividad a la sociedad hodierna.

El ser humano es vaciado de lo "humano", reducido a un ser atomizado sujeto a la acción de los dispositivos del poder. La genealogía foucaultiana pretende aprehender esas prácticas del poder sobre el sujeto y al mismo tiempo determinar sus estrategias y métodos. El fin es la transformación del concepto de ser individuo por el de ente anónimo, mediante tecnologías conductistas. Giorgio
Agamben señala que la noción de no-ciudadano es el prototipo del paradigma biopolítico de Occidente, el cual condujo a la creación de espacios de indistinción (campos de concentración, campos de refugiados, periferias urbanas convertidas en cloacas existenciales, etc.). El resultado es el despojo de humanidad (Agamben, 1998, p. 230). Estamos frente al hecho de que la seguridad está por encima de la persona, por ejemplo: el falso dilema de la venta de armas, fuente de empleo para algunos; para otros, una condena de muerte. Los discursos sobre pactos de seguridad laboral desoyen la voz del Galileo que dijo "el sábado está hecho para el hombre y no el hombre para el sábado" (Mc 2.27, 28).

La víctima es aquella persona de ayer y de hoy que es silenciada en el patíbulo de la historia de la violencia individual o estructural que ejercen los sistemas de explotación, por lo que está en estado continuo de no-existencia: la víctima se ha vuelto invisible para el sistema. La vida humana es ética porque busca el bien, la cual al ser negada por racionalidades del poder se convierte en un poder que desangra, tortura, vigila y castiga, pero lo más trágico es que roba la creatividad. En el fondo subyace la antigua y siempre nueva estrategia de dominio que consiste en identificar un enemigo y satanizarlo, no importa la veracidad, sino repetir la mentira hasta que se convierta en verdad. La filosofía no puede renunciar a mostrar los límites de la sociedad, debe forjar instrumentos de análisis de la acción sobre la realidad que interpela y, visibilizar a la víctima invisible rompiendo el silencio. Que resuene la declaración de Foucault: "los filósofos no nacen...son" (Foucault, 2012, p. 137). El principio ético fundamental es que la víctima es persona y la persona está a la base de lo social y lo político. 


\section{El psicopoder}

Los métodos de control psicológicos son más eficaces que los medios de coerción físicos, es la hipótesis observada por Foucault y plasmada en el texto citado Historia de la sexualidad. La hipótesis consistía en que la vida-cuerpo-especie debía ser sometida a control, a regulación, con el fin de que la sociedad fuera productiva y eficiente: un poder que gestiona la vida. El biopoder sobre el cuerpo social se traduce en un poder-saber que emplea las estrategias de la tecnología política para convertir el cuerpo en un instrumento de producción. La biopolítica dio paso a la psicopolítica, esta es la propuesta del filósofo coreano Byung-Chul Han. Su aportación, que brevemente reflexionamos ahora, es un paso hacia adelante en los análisis críticos de filosofía política desarrollados por M. Foucault, G. Agamben y Roberto Esposito (Esposito, 2012).

El pensamiento político general de Han se encuentra en su obra ¿Qué es el poder? (Han, 2016) $y$, de manera particular, en el caso del psicopoder, en el libro Psicopolítica. La noción de psicopolítica emerge de las investigaciones que ha realizado sobre la sociedad del rendimiento y de la trasparencia. El eje central del análisis es que el poder de la voluntad personal se extiende hacia de la voluntad de otros que la acogen voluntariamente, lo cual configura las acciones de control sobre los demás. El fin del psicopoder es que la libertad y la sumisión se constituyan como espacio de sentido. El espacio de sentido (finalidad) implementa estrategias sutiles y poco visibles: emplea la motivación y la optimización con el fin de excitar el éxito; actúa mediante la complacencia para convertir a los individuos en dependientes, en lugar de sumisos; dirige la voluntad mediante la seducción y evita la prohibición; no confronta al sujeto, sino que le ofrece mil facilidades; no impone el silencio a la psique, sino el compartir, el participar, el comunicar opiniones, (deseos, sueños, rabias, necesidades y preferencias); es invisible puesto que no niega la libertad, sino que la explota; anula la libre elección mediante la multioferta; y se sintetiza en las frases me gusta o Yes, I/we can (Han, 2018, p. 29-30).

El psicopoder se caracteriza por ser inteligente, en apariencia libre, amable, estimulante, seductor y, por tanto, no prohíbe, no coacciona, no disciplina. Y ha catalogado a la psique como fuerza de producción. La libre circulación de la información prescinde del contexto y drena la interioridad en el vacío cibernético. Aplica el principio económico de la trasparencia: comercializa el sensacionalismo del escándalo, ya que mostrarlo todo es la consigna; y liberar lo secreto para vigilar y controlar. Los medios digitales explotan lo no tematizado del mundo de la psique, es decir, manipulan el subconsciente para desplegar el rendimiento neoliberal. El trabajador se autoconvierte en empresario-empleado, por lo que se eliminan las clases sociales, y, el resultado es la autoexplotación. La competencia y la agresividad conducen hacia la sociedad deprimida. La conclusión es que la sociedad está envuelta por las tecnología del yo de Foucault al convertirse en instrumentos de domino de la psique individual y de los imaginarios sociales (Ortiz de Landázuri, 2017).

La biopolítica ha derivado en psicopolítica. El deber ético es sustituido por el poder sociopolítico que borra toda finalidad de bien y oscurece la verdad. Por tanto, el resultado es la autocoacción férrea e invisible de manera voluntaria y el modus vivendi es la libre competencia sin ningún límite, o sea, se instaura la dictadura del biocapital. La sociedad 
anónima ha hecho desaparecer al sujeto individual y social mediante la industria de la emoción, el juego y la comunicación. El bio/psico-capital sustituye a la trascendencia con la inmanencia, los ser(es) humanos son engullidos por el consumo y precipitados hacia al vientre del capital. La política es sustituida por la servidumbre voluntaria: la deuda externa de los países se convierte en la deuda "eterna"; se fomentan los tratados de libre comercio de mercancías-capital, pero que satanizan la libre circulación de las personas; y el ciudadano es reducido a consumidor/cliente. La indignación ética ha sido encapsulada en el océano de la información de las redes sociales que fomentan el sedentarismo político y perpetúan el statu quo.

El Big Data y el Big Brother sustituyen a la razón y, su cometido es identificar tendencias, responder a los interrogantes, posibilitar estrategias de mercado, controlar la información que es capital, evitar o resolver problemas, potenciar la toma de decisiones, garantizar la eficacia, vender felicidad, reducir los costos, generar necesidades y productos de consumo, privar de sentido moral al concepto de humanidad. Lo dicho es corroborable en las siguientes áreas: turismo, ocio, salud, administración pública, retail (comercio minoristas), manufactura telemétrica, publicidad, logs de TI (historial de las tecnologías de la información), call centers, finanzas, centros de sexness (sexualidad) o fitness (buena forma), etc. Estamos inmersos en la nube de la psicología digital que pretende manejar el tiempo biológico y psíquico en su dimensión de futurible, solo para proveer. Byung-Chul Han afirma que el "Big Data anuncia el fin de la persona y de la voluntad libre... es posible construir el psicoprograma individual...colectivo...quizás incluso el psicoprograma de lo inconsciente" (Han, 2018, p.
26, 38). La víctima es el logger (usuario) anónimo que navega evaporado en la nube del Big Data y es vigilado panópticamente en cada clic existencial. El sistema neoliberal descubre y emplea la psique como energía de producción para crear información y programas que sostienen el status económico.

En esta dinámica la vida buena asume los siguientes significados: prosperidad (el bienestar físico y financiero son una bendición de dios); empoderamiento-liderazgo (ideología); coaching (entrenamiento motivacional o programación); todo comportamiento humano "a-normal" es catalogado como síndrome (lo no controlado se denomina como enfermedad); el negocio del dolor y el sufrimiento (tecnología militar); y la violencia del rendimiento (estrés, esaurimiento nervioso, depresión, infartos). La programación neoliberal desarrolla la apología de lo positivo (optimismo desmedido), borra la memoria, narcotiza a la sociedad, induce el sueño social con fármacos, fomenta el sin sentido al vaciar de significado contenidos y conceptos, lava el cerebro (la tortura de la publicidad), y controla la comunicación, entre otros (Han, 2018, p. 47-57). La subjetividad libre y autónoma de la modernidad es explotada sin escrúpulos por la dictadura de la emoción: se consumen emociones, las cuales son infinitas y son un instrumento eficaz de control psicopolítico mediante el microtargeting o micro focalización (Han, 2018, p. 75-107). La meta del Big Data y del Big Brother es adueñarse del imaginario social y escribir el epitafio de la razón. Se puede afirmar que si existo es porque surfeo en la nube del Big Data. 


\section{El ecopoder}

El oikos (casa) griego representa a las personas y a los bienes que formaban la base de la sociedad griega. La etimología del término es importante, pero también su desarrollo a lo largo de la historia. En la actualidad somos testigos de la crisis de civilización que ha desembocado en una crisis ecológica, la cual puede culminar con la extinción de la especie humana. Estamos frente a la dicotomía economía y ecología, a pesar de que comparten la misma raíz griega eco. La crisis ecológica es producida por los hombres, por lo que esta hecatombe solo puede denominarse desastre humano (responsabilidad humana) y no catástrofe natural (sin responsabilidad humana). La economía se interesa por la producción de bienes, pero se olvida de las personas y, las personas individualizadas por la racionalidad económica niegan el logos ecológico sustentable, el cual hace posible la existencia razonable de la biosfera.

Enrique Leff ${ }^{3}$ no desarrolla de manera específica el concepto de ecopoder; sin embargo, su epistemología esta embebida por los análisis de M. Foucault. Esto permite realizar un análisis de las estrategias del poder-saber que influyen en la naturaleza (biopoder) y en la sociedad (psicopoder) desde la óptica ambiental. La tarea será posible gracias a la filosofía ambiental desarrollada por este investigador y la motivación que representa la Laudato Si del papa Francisco, el cual dice: "Hago una invitación urgente a un nuevo diálogo sobre el modo como estamos construyendo el futuro del planeta. Necesitamos una conversación que nos una a todos, porque el desafío ambiental que vivimos, y

\footnotetext{
${ }^{3}$ Enrique Leff es un filósofo ambientalista mexicano.
}

sus raíces humanas, nos interesan y nos impactan a todos" (Laudato Si, n. 14).

E. Leff, comentado la encíclica Laudato $S i$, señala que la modernidad se ha olvidado de la vida, no existe conciencia de los efectos ambientales que perjudican a la inmensa mayoría de la población. Los excluidos de este desastre ecológico somos todos, lo cual significa que en la dialéctica víctima-victimario está en juego la existencia de la especie humana y de la biosfera en su conjunto. Es una crisis generada por el quehacer humano, producto del dominio hegemónico sobre la tierra. El hombre, al olvidarse de la vida, soslaya indiferente que el cuidado de la biosfera preserva la existencia individual y social (Leff, 2015).

A la luz de la propuesta de E. Leff, se proponen tres vías de análisis del ecopoder desde las perspectivas de la epistemología, la economía y la política.

La racionalidad ambiental. La naturaleza y el ser humano son víctimas de las estrategias técnico-cientificistas y jurídico-económicas que justifican el saqueo de la naturaleza por medio de la racionalidad teórica-instrumental. La globalización tecno-económica de dominio ha acelerado la muerte entrópica del planeta mediante la objetivación de todos los entes (Leff, 2014, p. 12). Frente a esta encrucijada existencial Leff propone una racionalidad ambiental que parte de una ontología de la vida (ser/ente), proponiendo una epistemología que se caracteriza por ser un saber ambiental consciente de los efectos de las dinámicas de saber-poder y una ética de la responsabilidad de la alteridad del otro y de lo otro denominado ambiente. Esta aventura implica comprenderse en relación ecoético-política con el todo, asumir las condiciones entrópicas de la 
existencia, apertura al diálogo de saberes y sentidos, reconocer la pluralidad cultural, estar dispuesto a emprender acciones que preserven la vida y organizar políticamente a la sociedad bajo el principio ético de calidad de vida sustentable. Se invita a crear otro modo de ser, a construirlo mediante el diálogo plural del consenso y el disenso, en la recta actitud de buscar la verdad, en la conciencia responsable del respeto y el reconocimiento del intercambio dialógico que posibilita el saber ser humano.

Ecología y economía. El biocapital ha decretado que la realidad debe ser cuantificada y valorada por su valor de uso/útil, o sea, cosificar para comprar y vender, pero ¿se puede comprar la vida?, ¿cuál es el valor real de la extinción de una especie de la biosfera?, etc. El progreso-desarrollo como un dictador se apoltrona en el cientificismo, en la productividad económica y en el poder de la técnica. La relación entre ecología y economía parece un diálogo entre sordos, donde el concepto de los límites ha sido desterrado de la cultura. Lo políticamente correcto de la lógica de mercado justifica la acumulación destructiva de la biosfera y fomenta la degradación ambiental: desertificación, contaminación del agua y la atmósfera, calentamiento global, el aumento de los niveles de los océanos, los deshielos de los polos, la sobreexplotación de los ecosistemas marinos, las islas de basura que flotan en los mares, etc.

Se requiere desenmascarar la falacia de la disponibilidad infinita de los bienes del planeta, de la inmediatez de la regeneración de los bienes y el pretender que los efectos negativos sean absorbidos por la naturaleza como si fuese el proceso biológico de la fotosíntesis. Es necesario un proceso de deconstrucción y reconstrucción epistemológico en la interrelación ecología-cultura-economía que frene a la posverdad que se erige como verdad monetaria. La solidaridad ecológica universal es una exigencia cultural basada en la antropología y ontología del cuidado. Se debe plasmar en un paradigma de conversión que salvaguarde la vida redefiniendo nuevos modos-mundos de habitar el planeta Tierra, el cual es nuestra casa común (Pereira de Cunha et al., 2015, p. 26). La sustentabilidad implica la reflexión sobre los modos de apropiarse la relación sociedad-naturaleza desde los procesos ecológicos, culturales, jurídico-económicos, científico-tecnológicos, ético-políticos. Si la barca naufraga, todos nos ahogaremos en nuestra propia basura.

Política ecológica. La emigración masiva del campo a la ciudad exige una política del cuidado de la megalópolis, quizás, una metáfora a escala del regreso a la ciudad griega en este siglo. El hombre político debe comprender las condiciones termodinámicas-ecológicas y simbólico/culturales de la vida. El vivir bien de los pueblos originarios de América Latina, enseñanza antigua y siempre nueva, implica hacerse cargo del cuidado de la biosfera y todo lo que posibilita la vida. El bien común amalgama las posturas de Leff y del papa Francisco al señalar que la política y la economía deben estar al servicio de la vida. Las estrategias de sujeción y destrucción del mundo reflejan la voluntad de poder materializado en la inequidad, la exclusión, el consumismo, la atomización social, el auge de la violencia, el narcotráfico y la narcotización (drogas y fármacos), así como la zombización de la conciencia colectiva.

La reflexión ecológica implícitamente es una cavilación sobre la sociedad, es la escucha y mirada atenta a los fenómenos sociales que claman frente al dominio totalitario que destruye toda posibilidad de existencia y coexistencia con el otro y lo otro 
(naturaleza). La razón ambiental creativa debe reorientar la técnica, la ciencia, el mercado y la política. El no globalizar la indiferencia del papa Francisco se traduce en asumir la responsabilidad diferenciada y, en un diálogo franco y abierto entre las religiones, las ciencias y la filosofía, ante los retos ambientales actuales.

El miedo se ha convertido en la herramienta que somete al cuerpo y a la mente, lo cual legitima las estrategias de poder del modelo económico distributivo actual, por ejemplo: se acusa del desequilibrio ambiental al aumento de la población, pero el consumismo y la explotación de una minoría (transnacionales), al atribuirse el derecho de apropiación de los recursos ambientales sin ningún límite se convierten en fuentes de inestabilidad. La acción creadora está en marcha, ya que "otros mundos sustentables posibles están latiendo y actuando allí donde resuena el grito de la tierra y de los pobres, en los derechos y demandas de territorialización de los pueblos de la tierra, en la fuerza creativa e inventiva de los seringueiros de la cuenca amazónica, de las comunidades afrodescendientes del pacífico colombiano, de los pueblos mapuche del sur del continente, de los caracoles de los pueblos zapatistas" (Leff, 2015). La conclusión general de Leff es que la problemática ambiental es una crisis de civilización.

\section{Estrategias del ecopoder}

Desde esta fuerte convicción, basándonos en las aportaciones de Enrique Leff y J. Manuel Naredo $^{4}$, enunciaremos las premisas y estrategias de poder que subyacen en la actual crisis ecológica en tres áreas: epistemología, economía y ética-política (Leff, 2009; Naredo, 2007):

\section{a) Epistemología}

La razón imperante es anti-natura; la ruptura epistemológica provoca la lectura unidimensional de la realidad desde la sola categoría uso/ utilidad; la cosificación del ser; la racionalidad científica enmascara ideologías, valores e intereses de mercado; la irracionalidad se convirtió en razón (Marcuse, 2003); se obstruyen los procesos de desmitificar o deconstruir conceptos y lógicas de dominio; no interesa la verdad, sino lo políticamente correcto; la estadística sustituye a la historia; se analiza el efecto pero no la causa, por ejemplo: el calentamiento global es un efecto y no la causa del problema ecológico; se fomenta el relativismo y el reduccionismo para polarizar el consenso de la sociedad; la imagen y la terminología verde son difundidas como verdades, pero son pseudo verdades del mercado; se prescribe el somnífero de soluciones fáciles y final feliz; se utiliza el lenguaje soteriológico para prometer a los fuertes la libertad plena y a los desheredados la esperanza de un futuro de bienestar si trabajan para ello, pero no les dicen que no hay empleo; el lenguaje de la posverdad es vaciado de significado; y las decisiones son tomadas por el poder empresarial y político, etc.

\section{b) Economía}

El desquiciamiento de la explotación de los bienes naturales; el peligro latente de padecer una muerte entrópica por no respetar las dinámicas de los procesos y límites naturales; el mandato no escri-

${ }^{4}$ José Manuel Naredo es un economista español estudioso de la economía ecológica. 
to es mantener el statu quo del modelo económico; se esconde que las ciencias naturales han afirmado la inviabilidad del crecimiento sin límites; el adjetivo sostenible solo cubre la mentira de que el desarrollo salvará/preservará la humanidad; el problema de los residuos sólidos (tóxicos y radiactivos); se divulga la mentira que el desarrollo tecnológico es la panacea de la salvación; se instrumentaliza la psicología conductual para fomentar respuestas sociales a estímulos económicos; se construyen relaciones laborales de dependencia, por ejemplo, el salario adormece la creatividad; se fomenta el ahorro bancario en la sociedad, pero lo que esto significa es que los banqueros $u$ otros disponen de dinero ajeno para negocios/intereses personales o estructurales; el auge de la economía especulativa fomenta la impunidad; impera la hegemonía de la economía financiera sobre la economía comercial; el capitalismo hegemónico explota, desregula y privatiza en nombre de la libertad; el estado del bienestar es sustituido por una situación de precariedad; la economía es dogmática y doctrinaria porque suplanta a la física, la biología y la historia por medio de la apologética; el abandono del campo por las megalópolis; la ciudad es una bomba de tiempo ambiental, etc.

c) Ética y política

La pérdida del sentido de la existencia; la negación de la alteridad y la otredad ambiental; el control de la ética y la política por la razón económica instrumental; se crea el metarrelato de la mitología del crecimiento y la producción hasta el infinito; se transmiten cínicamente campañas de imagen para negar los problemas ambientales; la política está narcotizada por el lavado verde del cerebro; la indiferencia potencia la desigualdad; se manipula al poder político y el derecho positivo; los Estados permeables han sido sustituidos por las empresas transnacionales; en nombre de los derechos humanos o causas humanitarias se globaliza la dinámica financiera y militar; la avaricia depredadora del hombre lo autoaniquila; se produce una legión de desterrados y desarraigados, los expulsados del paraíso fiscal; el modelo impulsa la emigración internacional/nacional por medio del mass media; se predica el evangelio de la prosperidad; la terminología apocalíptica controla/fomenta el miedo, recuérdese que el miedo es una herramienta de control social; gobierna la ética universal del éxito, la cual esta dictada bajo el principio del coste-beneficio; el orden económico social requiere presencia militar y humanitaria global; la moral enseñada en centros educativos es que el poder es virtud porque el bien es poder, por lo cual, la riqueza es virtud/bendición, etc.

El elenco no es exhaustivo, pero sí muestra la panorámica en la que estamos llamados a definirnos en nuestras elecciones. El pensador austriaco Iván Illich (Illich, 1970) concluye que el homo sapiens se convierte en homo economicus, pero el resultado final es el homo miserabilis (Illich, 2010). El fin es salvar a la persona y salvaguardar a la naturaleza que es condición de posibilidad para la vida.

\section{Conclusión}

Toda relación injusta de poder-saber insustentable es fuente de violencia. La crisis termoecológica refleja la fractura en la relación sociedad y naturaleza. Por ello, el cambio climático es la alarma que anuncia que se está en los márgenes de un ecocidio que pone en peligro la vida y la vida humana. 
La persona es responsable moral de salvaguardar la integridad de la alteridad y la casa común. Por ello, la persona-víctima es principio transversal de la ética, ya que la auténtica vida humana es acción creadora que cuida de los vulnerables y del hábitat que es condición de posibilidad para la vida de la biosfera. La biopolítica de M. Foucault devela la genealogía y la arqueología histórica de las estrategias de poder-saber que tienen como fin gestionar la vida (controlando, administrando y regulando al cuerpo, a la psique y al hábitat). El desarrollo de este dispositivo condujo a concebir el cuerpo/psique como máquina y a la especie humana como industria. En suma, la conclusión lógica es que los seres humanos se convierten en el ADN de la producción (bio-psico-capital) y la naturaleza en el almacén de recursos ilimitados (falacia).

Los análisis críticos de la filosofía son necesarios para el florecimiento de la libertad-responsable del ser humano. Por tanto, la filosofía no puede claudicar en su tarea de develar y desconstruir la verdad, frente a neutralidades, indiferencias, controles, anestesias, violencias, vacíos, neuro programaciones conductuales, dictadura de las emociones, exclusiones, saqueos, insostenibilidades, etc. La filosofía posibilita otro modo de relación entre la sociedad y la naturaleza, a partir de la libertad y la responsabilidad del ser humano y de la comprensión de las condiciones termoecológicas propias de la naturaleza.

La evaluación de este proceso invita a cultivar las siguientes virtudes: aceptar el limite como nota no opuesta a la libertad, sino como condición de posibilidad para la vida; asumir la pluralidad cultural; reconocer la diferencia y complementariedad de la alteridad; y, salvaguardar la biosfera por su valor en sí, y en su valor para nosotros, ya que es condición para el vivir y convivir humano. Las ciencias y la tecnología, desde la responsabilidad humana, se caracterizaran, entonces, por su servicio de la vida. La filosofía por amor a la verdad debe desenmascarar al biopoder, al psicopoder y al ecopoder; es un deber ético-político que no puede ser eludido en este crepúsculo de la historia, ya que todos en diferente grado de responsabilidad somos víctimas, victimarios o cómplices de estrategias de bio-piso-eco-poder. Al fin de cuentas, salvar la biosfera es salvar al hombre y viceversa.

La bio-psico-eco-víctima es la persona sometida por las estrategias de poder-saber empleadas por autores intelectuales o materiales. Las estrategias de poder emplean las tecnologías-dispositivos para encadenar al cuerpo-psique (máquina) y a la especie humana (biocapital), es decir, se enjaula al cuerpo y se adiestra el inconsciente individual/ colectivo. La biopolítica y la psicopolítica se basan en el concepto de bio/pisco-poder para estructurar las técnicas de dominio sobre la sociedad (cuerpo y mente). La sentencia de esta dinámica será que todo aquel que no genere ganancia productiva terminará siendo desechado. La estrategia empleada actualmente se caracteriza por ser sutil, seductora, emotiva, y estafadora porque simula la libertad. $\mathrm{Y}$, se distingue por la pericia con la cual somete al cuerpo (dietas, sedentarismo, obesidad, gimnasios) y a la conciencia (estimula el subconsciente, nubla la mente, las elecciones y los sentidos). Sin duda, el psicopoder es mucho más eficaz que el biopoder, por ejemplo: el psicopoder-digital publicita seductoramente la libertad, pero emplea las trampas del Big Data (información) y el Big Brother (vigilar y controlar) en la sociedad de la trasparencia y el rendimiento económico. La víctima vulnerable ha perdido su capacidad de persona libre y creativa, 
capaz de recrear otros modos de ser, puesto que sus pensamientos han sido cibernética y conductualmente saboteados, en definitiva, se trata de una programación mental. La manipulación de los biocomportamientos y la psicoprogramación de las posibilidades han conducido a identificar a la economía como posesión, a la libertad como derecho y a la responsabilidad como control.

Los efectos del biopoder y el psicopoder están dañando irreversiblemente a nuestro hogar (la casa común - oikos), el planeta Tierra. La síntesis de estas vertientes, en sus efectos tóxicos, es el ecopoder. El ecopoder puso en marcha el ecocidio, promoviendo el exterminio de la biosfera y dictando la sentencia de muerte para las generaciones venideras al arrebatarles su futuro. La sobreexplotación de la naturaleza y la exclusión de las personas es una cuestión ético-política porque refleja el olvido de la vida, la inconsciencia de los efectos y la apatía ecológica. El poder debe llevar al ser humano a sentipensar queriendo la vida sustentable, por medio de una ética de la responsabilidad que siempre deberá enfrentar los siguientes temas: construir otro modo de relación sociedad-naturaleza, abrirse al diálogo plural de saberes, reconocer las diferencias del convivir con la alteridad y, coexistir sustentablemente en los ecosistemas de la biosfera exigiendo una reorganización ambiental. La Economía debe por un lado, retejer su relación con la Ética y la Política y, por el otro, renunciar a suplantar a la Historia, la Biología y la Física. La ruta es la inter-trans-disciplinariedad que restaura la relación oikos-ethos. El bio-psico-eco poder/saber refleja que se está frente a la exigencia epistémico-moral de implementar uno nuevo paradigma, basado en la solidaridad (Antropología), la vida (Ontología), el saber ambiental sustentable (Epistemología), para el bien del individuo-sociedad y la naturaleza (Ética/Política). Atreverse a escribir una historia ambiental biográfica, desde la relación sustentable con la naturaleza, es la tarea de nuestro siglo.

\section{Referencias}

Biblia, N. T. Proverbios. In: Biblia. Español. Biblia de Jerusalén. Traducción de: Huby, J. Bilbao, ES: Desclée de Brouwer, 1987. p. 1526.

Agamben, G. Homo sacer: el poder soberano y la nuda vida. Valencia, ES: Pre-textos, 1998.

Bazzicalupo, L. Biopolítica. Un mapa conceptual. Santa Cruz de Tenerife, ES: Editorial Melusina, 2016.

Benjamín, W. Tesis sobre la historia y otros fragmentos. México: Contrahistoria, 2005.

Esposito, R. Comunidad, inmunidad y biopolítica. Barcelona: Herder, 2012.

Foucault, M. Vigilar y castigar. México, D.F.: Siglo XXI Editores, 1976.

Foucault, M. Historia de la sexualidad 1: la voluntad de saber. México, D.F.: Siglo XXI Editores, 1977.

Foucault, M. El poder, una bestia magnifica: sobre el poder, la prisión y la vida. Buenos Aires, AR: Siglo XXI Editores, 2012.

Foucault, M. Historia de la sexualidad. 1. La voluntad de saber. Madrid: Siglo XXI Editores, 2016.

Han, B-C. Sobre el poder. Barcelona: Herder, 2016.

Han, B-C. Psicopolítica. Barcelona: Herder, 2018.

Illich, I. The dawn of Epimethean man and other essays. Cuernavaca: Centro Intercultural de documentation, 1970.

Illich, I. Needs, en SACHS, W. The development dictionary: a guide to knowledge as power. London: Zed Books, 2010.

Leff, E. Aventuras de la epistemología ambiental. México, D. F.: Siglo XXI Editores, 2006. 
Leff, E. Ecología y capital: racionalidad ambiental, democracia participativa y desarrollo sustentable. México, D. F.: Siglo XXI Editores, 2003.

Leff, E. El cuidado de la casa común y la apuesta por la vida: La Encíclica Laudato Si y el pensamiento ambiental. Clases Magistrales. 6. v. Cátedra Fray Bartolomé de las Casas. Chile: Universidad Católica de Temuco, 2015. Disponible en: $<$ http://repositoriodigital.uct.cl/handle/10925/1841>. Acceso en: may. 2019.

Leff, E. La apuesta por la vida: Imaginación Sociológica e Imaginarios Sociales en los Territorios Ambientales del Sur. México, D.F.: Siglo XXI Editores, 2014.

Leff, E. Racionalidad ambiental. México, D.F.: Siglo XXI Editores, 2009.

Leff, E. Racionalidad ambiental: la reapropiación social de la naturaleza. México, D. F.: Siglo XXI Editores, 2004.

Marcuse, H. Razón y revolución. Madrid:Alianza, 2003.

Mendieta, E. «Hacer vivir y dejar morir»: Foucault y la genealogía del racismo. Tabula Rasa, 6, 138-152, 2007. Disponible en: www.scielo.org.co/scielo.php?script=sci_arttext\&pid=S1794-24892007000100007

Mitzman, A. La jaula de hierro: una interpretación histórica de Max Weber. Madrid: Alianza, 1976.
Naredo, J. M. Raíces económicas del deterioro ecológico y social: más allá de los dogmas. Madrid: Siglo XXI Editores, 2007.

Ojaide, T. No tienes que ser. Traducción de Ríos, N. In: WPM - World Poetry Movement. Antología Internacional de Poemas para la justicia social en el mundo. 2013 [1947]. Disponible en: <https://www.wpm2011.org/es/node/363>. Acceso en: abr. 2019.

Ortiz de Landázuri, M. C. De la biopolítica a la psicopolítica en el pensamiento social de Byung-Chul Han. Athenea Digital, 17(1), 187-203, 2017. Disponible en: http://atheneadigital.net/article/viewFile/v17-n1-cruz/1782-pdf-es

Osorio, J. Biopoder y biocapital. Argumentos, 19(52), 77-98, 2006. Disponible en: www.scielo.org.mx/scielo.php?scrip$\mathrm{t}=$ sci_arttext\&pid=S0187-57952006000300005

Pereira de Cunha, B.; Augustin, S.; Lima, L. G. D.; Costa, N. R. A. da (Orgs.). Os saberes ambientais, sustentabilidade e olhar jurídico: visitando a obra de Enrique Leff. Caxias do Sul: Educs, 2015.

Sobrino, J. Fuera de los pobres no hay salvación: pequeños ensayos utópico-proféticos. Madrid: Trotta, 2007. 